rioro se desea preservar mediante una réplica? Es algo que no podemos afirmar categóricamente ya que no disponemos de más pruebas, pero que dadas las evidentes coincidencias, consideramos interesante tener en cuenta.

También en el mismo Archivo y dentro del Códice $2 .^{\circ}$, datado por Leclercq en el siglo XIII, pero adelantada recientemente su cronología a la duodécima centuria ${ }^{53}$, queda recogido un tratado sobre el segundo de los aspectos que ha centrado de manera más amplia nuestra atención: la Trinidad. El folio 80 queda encabezado del siguiente modo: «Incipiunt capitula primi libri sententiarum de Misterio Trinitatis» ${ }^{54}$ confirmando de este modo el interés especial mostrado por el cabildo calceatense por la cuestión trinitaria desde sus orígenes que les llevó incluso a hacer de ésta la advocación del altar principal del templo.

Expuestas así las cosas, no quedaría sino tratar de averiguar cuál de los tres conjuntos escultóricos a los que nos hemos venido refiriendo a lo largo del texto fue creado en primer lugar y pueda ser considerado así el modelo de los otros dos. Dada la evidente vinculación técnica y la comunidad de estilo apreciable entre ellos, productos todos de los años finales del siglo xII, deberá ser un profundo análisis estilístico comparativo, y no es éste el lugar para ello, el que determine a quien corresponde la primacía y, con ello, la creatividad iconográfica que ha sido el objeto de este estudio.

Marta Poza Yagüe

Lda. Universidad Autónoma de Madrid

\title{
MISCELÁNEA SOBRE ESCULTURA GENOVESA EN ESPAÑA ${ }^{1}$
}

El estudio de obras italianas que de manera ininterrumpida fue llegando a España se viene haciendo desde hace ya muchos años. Pero se han estudiado preferentemente los grandes conjuntos sepulcrales o retablísticos tallados en mármol ${ }^{2}$ y se ha prestado menor atención a la escultura religiosa devocional que también llegó en gran cantidad y que ejercerá su influencia entre los artistas de la manera tradicional ${ }^{3}$. En este aspecto las zonas italianas para nosotros más interesantes han sido Génova y Nàpoles desde donde, por los más diversos conductos, nos llegó un elevado número de piezas.

Como una breve aportación más al catálogo genovés pretendemos con estas líneas dar a conocer unas piezas que no tienen, tal vez, más en común que el conservarse en distintos lugares de la Comunidad castellano-manchega. De todas, posiblemente, la de más interés y, por otra parte, la única que está plenamente documentada es el delicioso boceto de la Virgen con el

${ }^{53}$ López de Silanes, C. y Sáinz Ripa, E., op. cit., vol. I, p. 261.

${ }^{54}$ Ibídem.

1 Este trabajo forma parte de un proyecto de investigación financiado por la DGES (PB 98-0708).

Deseamos agradecer al Ilmo. Sr. D. Santos Saiz-Gómez, deán del Ilmo. Cabildo Catedral de Cuenca, la amable colaboración prestada para el estudio de algunas de estas obras.

${ }^{2}$ La bibliografía sobre el tema es ya muy numerosa. Solamente queremos destacar la tan conocida del Marqués de Lozoya: Escultura de Carrara en España, C.S.I.C., Madrid, 1957 y López Torrijos, Rosa: «La Scultura Genovese in Spagna», en La Scultura a Genova e in Liguria. Dalle Origini al Cinquecento, Vol. I, Génova, 1987.

${ }^{3}$ Como un gran esfuerzo en este sentido debe ser destacada la obra de Aranda Linares, Carmen. Hormigos Sánchez, Enrique y Sánchez Peña, José Miguel: Scultura Lignea Genovese a Cadice nel Settecento. Opere e Documenti, Génova, 1993. 
Niño acompañada por ángeles de la gran medalla que preside el retablo mayor de la Catedral de Cuenca, obra del escultor genovés Pasquale Bocciardo (1719-1791). Toda la trayectoria de esta obra ha sido ampliamente estudiada y documentada por José Luis Barrio Moya ${ }^{4}$ que, sin embargo, no dio con el boceto.

La obra de escultura del retablo mayor de Cuenca, diseñado por Ventura Rodríguez, se contrataba en 1756. Las gestiones con el escultor P. Bocciardo fueron llevadas a cabo por el broncista Juan Bautista Verda que le encargaba unos bocetos o modelos al tiempo que se le enviaba copia de los dibujos de Ventura Rodríguez para que se ciñera en lo posible a ellos. En julio de ese año se tenían noticias de la intención del envío desde Génova de los bocetos que embarcaba J. B. Verda el 2 de agosto. El 25 de septiembre éstos se presentaban al Cabildo para que, una vez examinados, se decidiese sobre ellos. La decisión definitiva parece estuvo en la opinión del obipo don José Flórez Osorio, que fue favorable a que se realizaran y se pusiese la obra en marcha. De los modelos, en plural, que parece llegan de Génova, el que ahora se estudia es el de la medalla que preside el retablo con la Virgen y el Niño adorados por una serie de ángeles. Está trabajado en barro, como dice la documentación, sobre el que se ha pintado en gris con una pintura o barniz brillante. El boceto, mide $0,61 \mathrm{~ms}$. de alto $\times 0,37 \mathrm{de}$ ancho, se ha encajado en un estuche de madera con tapa de cristal y se encuentra enmarcado con un espléndido marco de rocallas tan habituales en la Cuenca de estos años. Las variaciones con la obra definitiva, que sí existen, son escasas. La mayor novedad es el distinto planteamiento de la colocación de las figuras, que en la obra definitiva se ubican en un espacio totalmente cerrado y en el boceto en un espacio abierto por el fondo y lateral, donde se puede ver un paisaje abocetado poblado de rocas y árboles con un cielo despejado. Las formas arquitectónicas que acogen las figuras son mucho más sólidas en la obra acabada, recordando soluciones como las del retablo de la Capilla de la Merced de la iglesia de San Ambrosio de Génova, obra de Antonio Ponsonelli ${ }^{5}$, mientras en el boceto se limitan a un simple telón de fondo. Las figuras presentan diferencias que sólo afectan a determinadas posturas o gestos. El pequeño relieve resulta una obra delicada y bella y su mismo tamaño lo acerca más a la órbita del rococó que la obra definitiva impregnada ya, como muy bien señala Barrio Moya, de un cierto academicismo ${ }^{6}$. La pieza encaja muy en la línea de lo documentado de Bocciardo singularmente de las Inmaculadas conservadas en la Capilla del Conservatorio delle Fieschine, en Génova, o de la iglesia parroquial de Squaneto, cuyos rasgos faciales son en todo semejantes. Por lo que respecta a los ángeles arrodillados a sus pies tienen mucho en común con los conservados en el Museo de S. Agostino de Génova ${ }^{7}$.

Aspecto que, al parecer, no se ha tratado es el hecho de hasta qué punto Bocciardo se pudo ver influenciado por los dibujos de Ventura Rodríguez que, ya hemos visto, se le envían. Es precisamente en la medalla donde el escultor se aparta más de ellos. El tema, que debía ser el de la Natividad, queda perfectamente claro en el dibujo del arquitecto, mientras que en la obra definitiva se diluye y se simplifica al máximo. No obstante, sí está inspirada en el dibujo enviado la figura de la Virgen con el Niño en los brazos y los dos ángeles mancebos que en el dibujo son dos figuras humanas. El fondo, muy despejado, ideado por Ventura Rodríguez está

\footnotetext{
${ }^{4}$ Barrio Moya, José Luis: «El escultor genovés Pasquale Bocciardo y sus obras en el retablo mayor de la Catedral de Cuenca», Academia, n..$^{\circ}$ 75, 1992, pp. 265-294 y «Las obras de Ventura Rodríguez en Cuenca», en el catálogo de la exposición El Arquitecto D. Ventura Rodríguez (1717-1785), Madrid, Museo Municipal, 1983, pp. 259-269.

${ }^{5}$ Franchini Guelfi, Fausta: «Giacomo Antonio Ponsonelli architetto decoratore», Studi in menmoria di Teofilo Ossian de Negri, Génova, 1986, pp. 129-141.

${ }^{6}$ Barrio Moya, J.L.: «El escultor genovés Pasquale Bocciardo...», p. 287.

7 Belloni, Venanzio: La Grande Scultura in Marmo a Genova (Secoli XVII e xvIII), Génova, 1988 y Franchini Guelfi, Fausta: «Il Settecento. Theatrum Sacrum e Magnifico Apparato» en La Scultura a Genova e in Liguria dei Seicento al Primo Novecento, vol. II. Genova, 1988, pp. 215-293.
} 

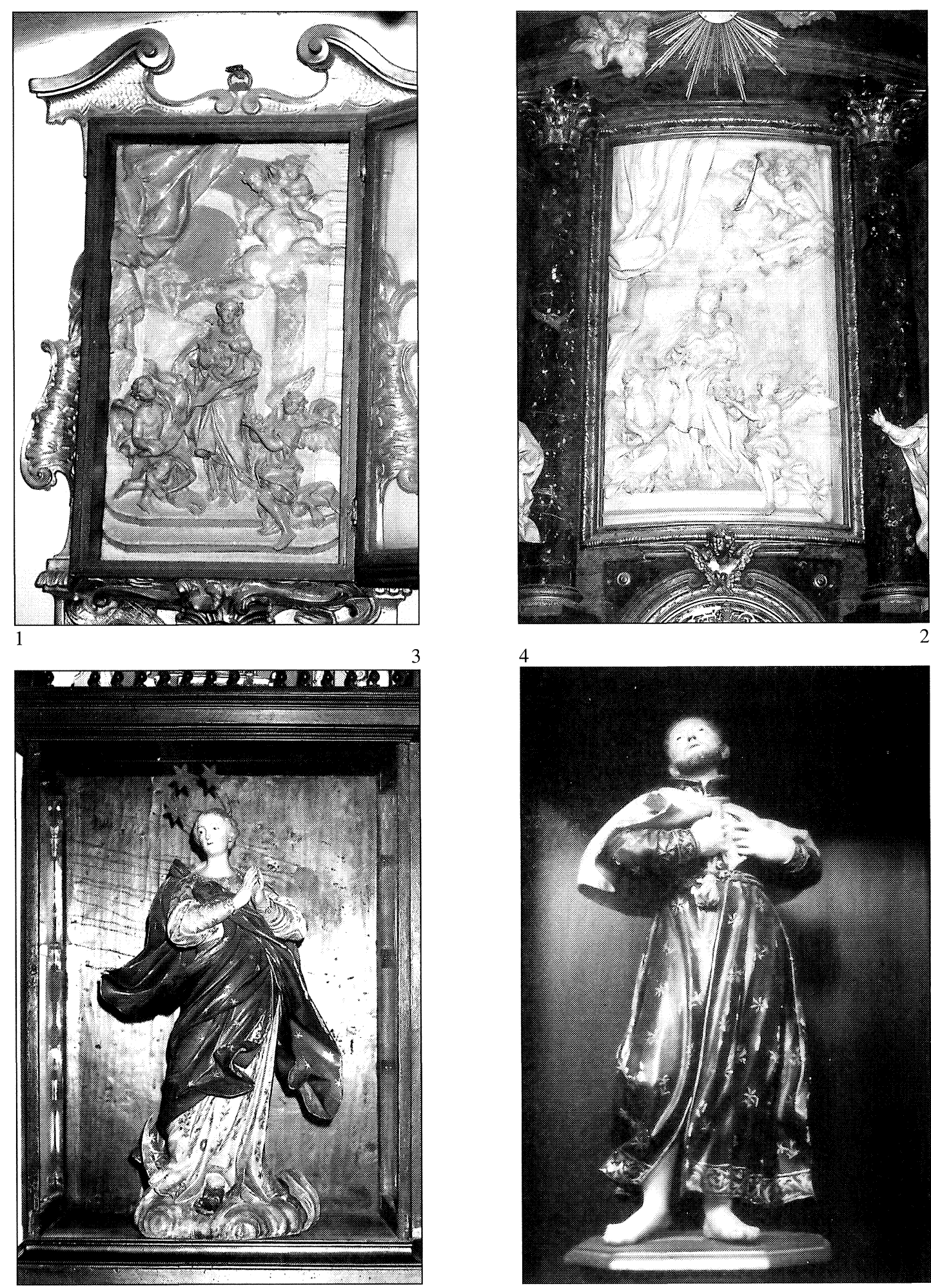

Fig. 1. Pascuale Bocciardo: Boceto de medalla del retablo mayor. Cuenca. Catedral.

Fig. 2. Pascuale Bocciardo: Medalla del retablo mayor. Cuenca. Catedral.

Fig. 3. Anónimo genovés: Inmaculada. Cuenca. Catedral.

Fig. 4. Anónimo genovés (?): San Francisco Javier. Cuenca. Catedral. 
más en consonancia con el boceto que con la obra definitiva que, como hemos visto, se sitúa en espacio cerrado. Ya en dibujo enviado al Cabildo el 22 de mayo de 1756, al parecer del propio Bocciardo, se indica «que parece tiene menos obra que el que tiene puesto en la planta $\mathrm{dn}$. Bentura Rodriguez» ${ }^{8}$.

En la misma Catedral de Cuenca, sobre una de las bellas cajoneras de la sacristía, se conserva una Inmaculada que recuerda estrechamente el mundo genovés y que resulta ajena a lo español de finales del XVII o comienzos del XVIII. Mide $0,70 \mathrm{~ms}$. de altura y su buena conservación acentúa todos sus valores plásticos. La figura se encuentra en la estela de las obras creadas en Génova por Pierre Puget y su círculo de discípulos o seguidores como Filippo Parodi, Giacomo Antonio Ponsonelli, los Schiafino y Antón María Maragliano ${ }^{9}$. El efecto de dinamismo que la escultura transmite se logra por el movimiento desenfrenado del manto que, como un torbellino, la envuelve. El rostro de óvalo muy redondeado y de formas llenas, el pelo rubio recogido tras la nuca dejando libre el cuello que el escote redondeado acentúa son características muy genovesas y que en España estamos más o menos acostumbrados a ver a través, entre otros, del marsellés Antonio Dupar ${ }^{10}$. El modo de vestir mostrando las mangas de la túnica recogidas y esas manos exquisitamente trabajadas, con los dedos que sólo se unen en una especie de leve aleteo, son elementos foráneos a lo español castizo.

Sobre la misma cajonera en que se expone esta Inmaculada, como formando pareja con ella, se exhibe otra imagen de San Francisco Javier que también nos parece genovesa o al menos italiana, dado que tiene algunas características ajenas a lo español conocido. El santo, mide 0,64 cms., aparece erguido, vestido con traje de peregrino de túnica corta, que deja ver sus pies desnudos y se abre ligeramente al impulso del movimiento al andar, y una amplia esclavina abierta por el centro para dejar libres los brazos y manos que abren la túnica para liberar el fuego ardiente del pecho. Por la parte de atrás, apenas visible, lleva caído un sombrero negro que recoge con grueso cordón. El rostro, de ligera barba, se alza y echa violentamente hacia atrás buscando el cielo en una especie de rapto. La policromía resulta especialmente curiosa, túnica de intenso azul oscuro salpicada de flores doradas y bordeada de una rica cenefa y esclavina blanca.

Otra imagen de Inmaculada que responde al mismo espíritu guardan en clausura las Madres Capuchinas de Toledo ${ }^{11}$. Ambas están plantadas en idéntico contraposto y ambas pisan la cabeza de dragón de la serpiente de idéntico modo. Ambas visten de idéntica manera. La forma de cabeza y rostro es también la misma, aunque la de las Madres Capuchinas tiene una mirada más vivaz y no muestra esta lejanía de la conquense, y ambas peinan el cabello del mismo modo y muestran idéntico cuello despejado debido al redondeado escote. La de Toledo tiene adheridas a la nube sobre la que se alza unas cabecillas de serfaines de rostro vivaracho que no aparecen en la conquense. El santo se mueve violentamente hacia el lado derecho como impulsado por idéntico viento ${ }^{12}$. La policromía es, sin embargo, más simple y de tonos suaves

\footnotetext{
8 Barrio Moya, J.L., o.c., p. 287.

9 Belloni Venanzio, o.c.; Franchini Guelfi, Fausta, o.c., y «Anton Maria Maragliano e la Committenza Francescana Genovese», La Casana, Anno XXXVIII, 1996, pp. 22-31. VV.AA., Catálogo de la exposición Pierre Puget. Un artista francese e la cultura barocca a Genova, Ed. Electa, 1995.

${ }^{10}$ Sobre Dupar ver, entre otros, López Jiménez, J. C., «Antonio Dupar el escultor Berninesco», Rev. Murcia, n. ${ }^{\circ} 7,1976$ y Margelina, Virginia de; Molina, Isabel, y Sánchez Rojas, M. ${ }^{a}$ Carmen: «Las relaciones entre Francisco Salzillo y la escultura del siglo XviII», en catálogo de Francisco Salzillo y el Reino de Murcia en el s. XvIII, Murcia, 1983, pp. 127-142.

11 Nicolau Castro, Juan, Escultura toledana del siglo XVIII, Toledo, IPIET, 1991.

12 Este movimiento del manto es algo que pasará al arte español de la segunda mitad del siglo xviII y que podemos ver en autores muy ligados al mundo de la Academia madrileña y valenciana, tales como Manuel Álvarez, Isidro Carnicero, Manuel Tolsá o Ignacio Vergara, entre otros. Todos los autores que han tratado el tema apuntan a su inspiración en el mundo genovés de Pierre Puget. Ver Tárraga Baldó, M. ${ }^{a}$ Luisa, «España y América en la escultura cortesana de la segunda mitad del siglo XvIII: Corrientes recíprocas de influencia», en Relaciones artísticas entre España y América, C.S.I.C., 1990, pp.
} 
y planos, y no descartamos que haya sido repintada debido al carácter de cierta modernidad que sus colores transmiten.

En el mismo monasterio de Madres Capuchinas se conserva un Crucifijo con María Magdalena abrazada a la cruz y arrodillada a sus pies que recuerda muy estrechamente obras seguras genovesas al tiempo que se aparta de lo español del momento. Mide el conjunto $1 \mathrm{~m}$. y el Crucificado $0,45 \mathrm{cms}$. Se trata de un Cristo clavado en la cruz de esbeltísimas y elegantes proporciones que desplaza marcadamente las caderas hacia el lado derecho arqueando todo el cuerpo en esa dirección. Es muy típica la manera de colocar las piernas cruzando los pies en marcada aspa y dejando la pierna derecha bajo la izquierda que arquea y eleva la rodilla. Inclina la cabeza sobre el hombro izquierdo y peina largos cabellos ondulados, tratados con marcados surcos, que caen blandamente hacia el mismo lado. Es típico también el modo en que se recoge el paño de pureza atado con cuerda y recogido en la parte central mientras flota libremente hacia la derecha.

Arrodillada a sus pies se sitúa la Magdalena, que abraza la cruz con el brazo derecho mientras extiende el izquierdo en gesto de súplica. Va vestida al modo popular con justillo que se ata con cordón en la parte del pecho dejando ver la camisa. El pelo está también trabajado a mechones de surcos profundos. La policromía es de tonos planos al modo como vemos en la Magdalena del Descendimiento de la iglesia genovesa de la Visitación ${ }^{13}$.

Se aprecia claramente en este grupo la manera de trabajar de un Antón M. Maragliano y la estrecha relación del Crucifijo con el Cristo de la Salud de la iglesia del Carmen de San Fernando de Cádiz ${ }^{14}$. Menos fina de talla nos parece la figura de María Magdalena.

En la pequeña capilla del Palacio de El Viso del Marqués en la provincia de Ciudad Real ${ }^{15}$, fundación de Don Álvaro de Bazán, I Marqués de Santa Cruz, donde se guardan sus restos, se da culto, desde hace ya muchos años, a una hermosa Virgen con el título del Rosario de la que en ocasiones se comenta, con evidente anacronismo, acompañó a Don Juan de Austria en la batalla de Lepanto. La imagen, cuya fotografía ya fue publicada en 1966 por don Crisanto López Jiménez ${ }^{16}$, estuvo durante años en el Museo Naval de Madrid y con posterioridad fue llevada al palacio manchego, Archivo General de la Marina Española. Al parecer, procede de la capilla de las galeras del Puerto de Santa María y, como ya apuntó también don J.C. López Jiménez, es copia de la Virgen de Portacoeli o del Carmen de la iglesia de Nuestra Señora del Carmen de Cádiz. Imagen espléndida que, según recientes investigacionews, se atribuye con fundamento al escultor genovés Francesco Galleano ${ }^{17}$, discípulo de Antón María Maragliano, escultor afincado en Cádiz donde muere en 1753. La imagen de El Viso del Marqués, de aproximadamente un metro de altura, parece copia antigua; sigue en todo a la original y también presenta una rica policromía, pero, por su menor calidad y finura de talla, pertenecerá a un desconocido copista. En algunas zonas el color está muy oscurecido, sobre todo en la pareja de juguetones angelillos que aparecen a los pies en la zona izquierda. Falta la cabeza de angelillo que el original lleva en el lado derecho, aunque es muy posible que se haya perdido, porque queda espacio suficiente en la nube que pisa la Virgen. Copias de la imagen de la iglesia del Carmen abundan en capillas y colecciones privadas de Cádiz y se siguen realizando

217-272. VV.AA., Tolsá, Gimeno, Fabregat. Trayectoria artística en España. Siglo xviII, Generalitat Valenciana, 1989. Estella, Margarita, «Miscelánea de escultura del siglo XviI» en El Arte en tiempos de Carlos III, C.S.I.C., 1989, pp. 245-256.

${ }^{13}$ Franchi Guelfi, Fausta, «Il Settecento. Theatrum Sacrum e Magnifico Apparato...», lám. 336 y «Antón María Maragliano e la Committenza Francescana...».

14 Aranda, Carmen; Hormigo, Enrique, y Sánchez, José Miguel, o.c., p. 68, láms. I y IV.

15 López Torrijos, Rosa, «Il Palazzo di El Viso del Marqués», en La Pittura del Cinquecento a Genova, Génova, 1999.

${ }^{16}$ López Jiménez, José Crisanto, Escultura Mediterránea. Finales del siglo xvii y xviii, Murcia, 1966.

17 Aranda, Carmen, y otros, o.c., pp. 69-70 y láms. II y III. 


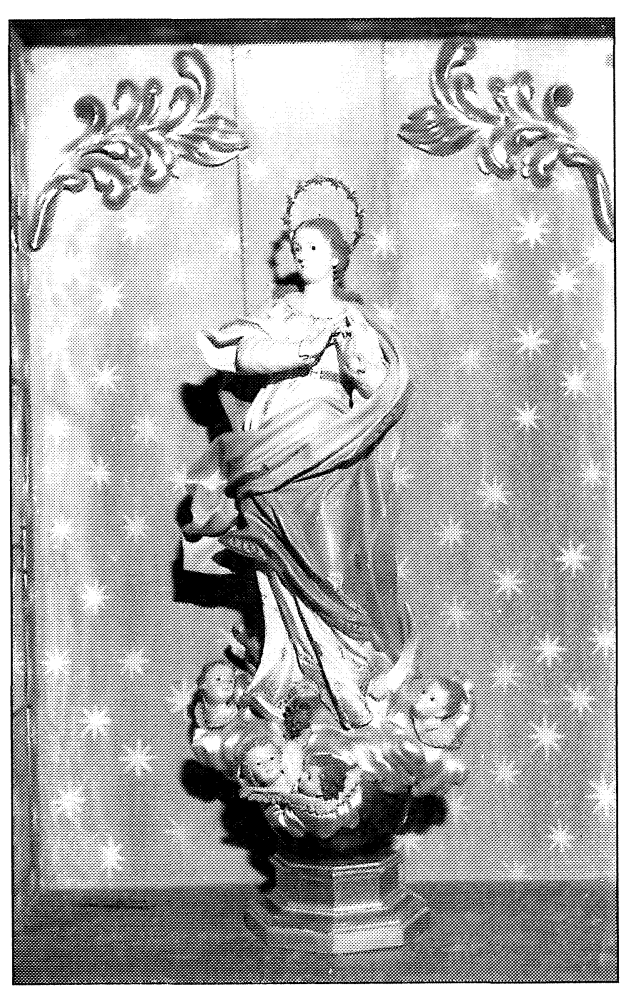

5

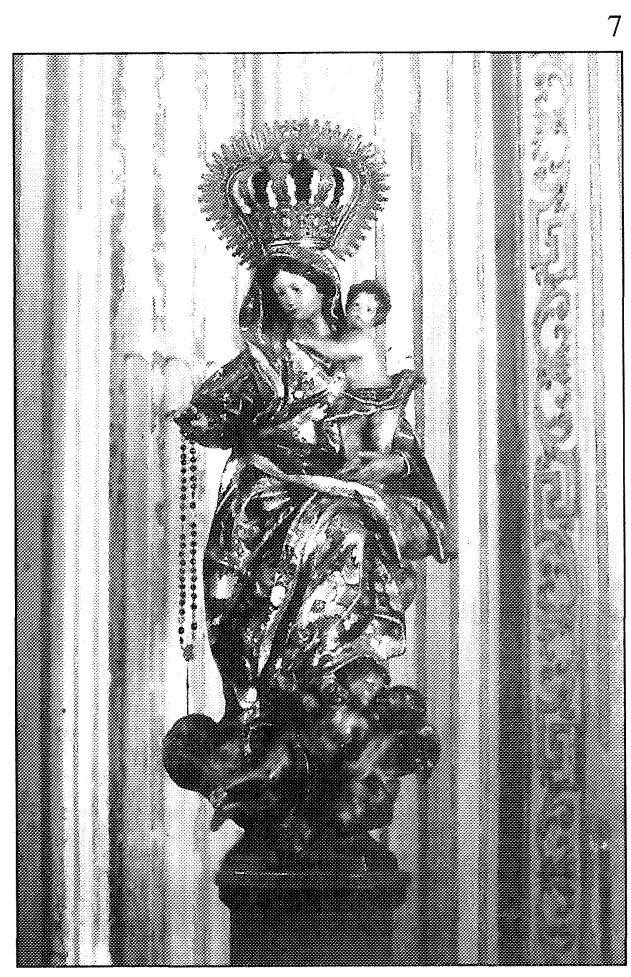

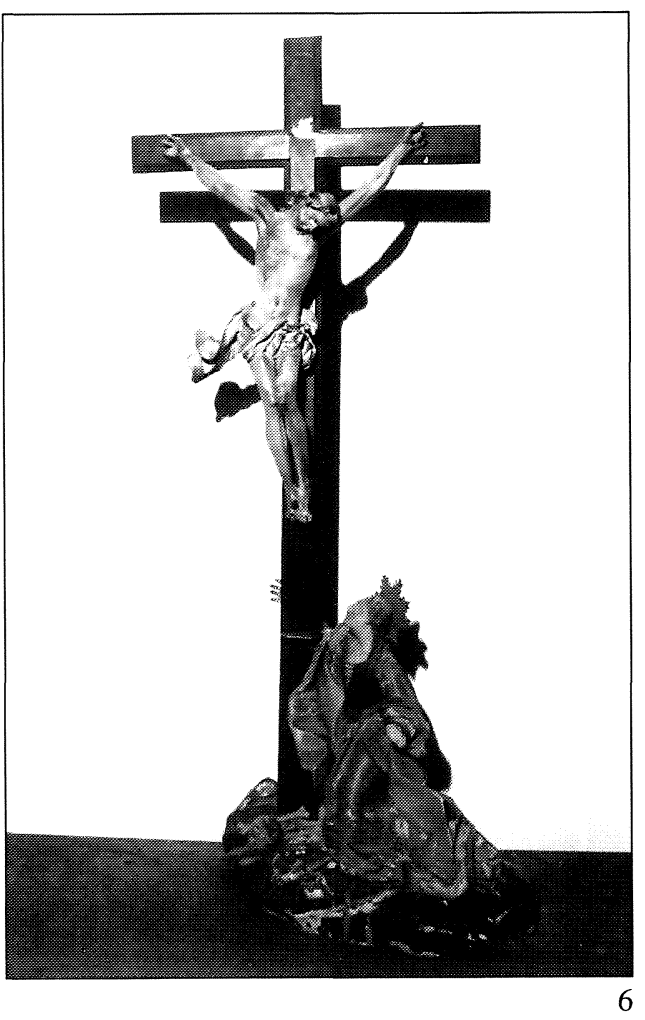

8

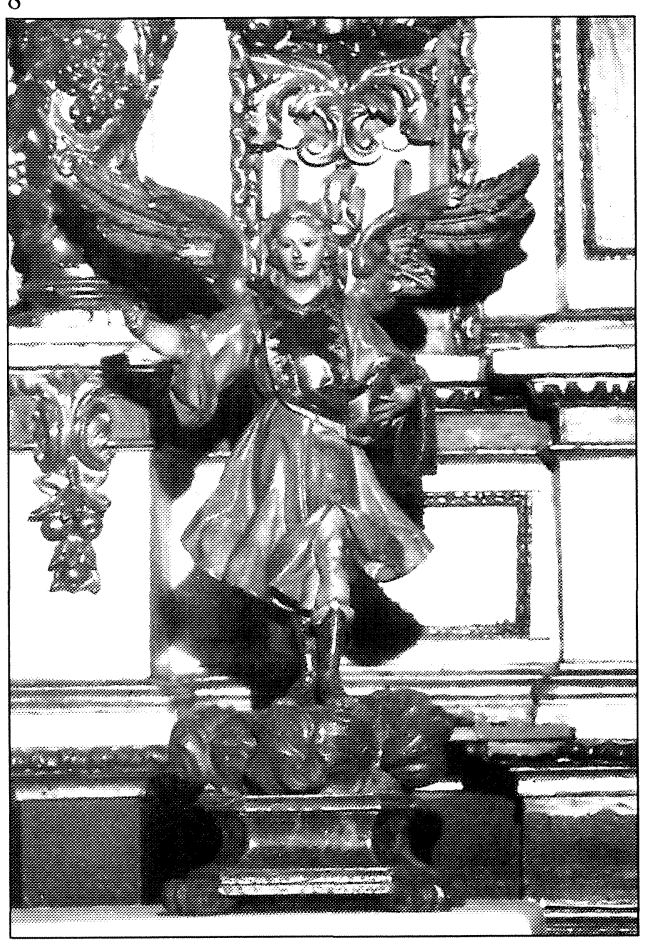

Fig. 5. Anónimo genovés: Inmaculada. Toledo. Madres Capuchinas.

Fig. 6. Círculo de Antón M. ${ }^{a}$ Maragliano: Crucifijo con la Magdalena. Toledo. Madres Capuchinas.

Fig. 7. Anónimo: Virgen del Rosario (?). Ciudad Real. Palacio de El Viso del Marqués.

Fig. 8. Anónimo: San Rafael. Talavera de la Reina. Ermita de la Virgen del Prado. 
hasta nuestros días ${ }^{18}$. Una de ellas, posiblemente ya moderna, hemos localizado en sitio tan apartado de la ciudad andaluza como el Monasterio de Carmelitas Descalzas de la villa de Arenas de San Pedro, en la provincia de Ávila, que, según nos ha informado amablemente su superiora, permanece allí desde la fundación del convento en 1954 y fue comprada, al parecer, en Sevilla.

Y una prueba de cómo obras genovesas inspiraban a escultores españoles la hemos encontrado en un San Rafael que, procedente del desaparecido Hospital de San Juan de Dios de Talavera de la Reina, se conserva hoy en retablo lateral de la ermita de Ntra. Sra. del Prado ${ }^{19}$. Está directamente inspirado en el de Antón M. ${ }^{a}$ Maragliano que recibe culto en la iglesia del Hospital de San Juan de Dios en Cádiz ${ }^{20}$. La calidad del que presentamos es muy inferior a la exquisita obra gaditana pero su inspiración en él es evidente. Se eleva sobre idéntica peana de nubes, la túnica corta se abre para dar salida a las piernas que se muestran hasta bien entrado el muslo calzadas con idénticas botas. Las mangas de la túnica, de color rosa pálido, se recogen de idéntica manera sobre el codo y sobre ésta lleva el negro escapulario de los hermanos hospitalarios que recoge con la mano izquierda. La cabeza con la mirada dirigida hacia abajo también se inspira en el gaditano, si bien tiene distinto el color del pelo, oscuro el de Cádiz y rubio claro el talaverano. Al ser imágenes veneradas en hospitales de la misma orden, el camino para su inspiración es el repetido una y otra vez dentro de una misma casa religiosa. Publicada hace ya algunos años, la situábamos entonces en el círculo de un Luis Salvador Carmona, atribución que tal vez deberá revisarse.

Rosa LóPez TorRijos (Universidad de Alcalá) y Juan Nicolau Castro (Dr. por la Universidad Autónoma de Madrid)

\footnotetext{
${ }^{18}$ Idem, pp. 70 y 108, y López Jiménez, J.C., o.c.

19 Nicolau Castro, Juan, o.c.

20 Méndez-Cabeza Fuentes, Miguel, Guía de Talavera de la Reina, 1999.
} 